\title{
Hypertension in Primary Open Angle Glaucoma
}

\author{
Suprada Pokharel,' Dakki Sherpa, ${ }^{2}$ Om Krishna Malla' \\ 'Department of Ophthalmology, Kathmandu Medical College Teaching Hospital, Kathmandu, Nepal, ${ }^{2}$ Depatment of \\ Ophthalmology, National Academy of Medical Sciences, Kathmandu, Nepal.
}

\section{ABSTRACT}

Introduction: The impact of vascular factors in POAG is well known and controversial. Some reports have shown high blood pressure in POAG, some low systolic blood pressure and some described no difference in blood pressure between POAG and controls. However decreased ocular perfusion pressure was found in most of the studies. Our study aims to assess the role of hypertension in POAG.

Methods: It was cross-sectional case-control hospital based study carried out from $1^{\text {st }}$ June 2012 to $1^{\text {st }}$ June 2013. There were 40 cases and 100 controls included in the study. The role of hypertension were compared with those hypertensive patients with glaucoma (cases) and hypertensive patients without glaucoma (controls).

Results: Age above 50 years (odds ratio: 4.827 with 95\% CI 1.862-12.517), male genders (odds ratio: 3.10 with 95\% CI 1.356-7.146) and low diastolic perfusion pressure (odds ratio: 3.857 with $95 \% \mathrm{CI}$ 1.362-11.224) showed strongly positive association with POAG. High systolic blood pressure (odds ratio: 1.476 95\% CI 0.627-3.476), high diastolic blood pressure (odds ratio: 1.348 95\% CI 0.587-3.096) and low systolic perfusion pressure (odds ratio: 1.8661 with 95\% CI 0.649- 5.335) were weakly associated with glaucoma in our study.

Conclusions: Age above 50 years, male gender and low diastolic perfusion pressure were strong risk factor for the development of POAG.

Keywords: diastolic blood pressure; diastolic perfusion pressure; POAG; systolic blood pressure; systolic perfusion pressure.

\section{INTRODUCTION}

Systemic hypertension may increase the risk of primary apen angle glaucoma (POAG) by damaging the small blood vessels of the optic disc. Moreover, studies have shown BP and IOP levels are positively associated. ${ }^{1-3}$ Some authors have described association of glaucoma with low systolic blood pressure, ${ }^{4}$ some, low blood pressure in normal tension glaucoma and high blood pressure in POAG, ${ }^{5-7}$ and others have reported no difference in blood pressure in glaucoma and control. ${ }^{8,9}$ A reduced ocular perfusion pressure in POAG patients compared with normal controls was reported in a number of studies. ${ }^{10,11}$ A low perfusion pressure impairs the perfusion of the optic nerve and causes glaucomatous loss of the visual field.

This study is carried out to detect role of hypertension and perfusion pressure in POAG and control group in our context.

Correspondence: Dr. Suprada Pokharel, Kathmandu Medical College Teaching Hospital, Kathmandu, Nepal. Email: supranp@yahoo. com. 


\section{METHODS}

This was cross-sectional case-control hospital based study. Hypertension patients attending OPD of ophthalmology department of Kathmandu Medical College Teaching Hospital and OPD of Nepal Eye Hospital were evaluated for this study from $1^{\text {st }}$ June 2012 to $1^{\text {st }}$ June 2013. The role of hypertension was compared with those hypertensive patients with glaucoma (cases) and hypertensive patients without glaucoma (controls). Cases included in the study were diagnosed glaucoma under treatment. Controls were patients attending eye OPD for fundus evaluation or for refractive error. Cases and controls were matched for age (three or four years above and below) and for sex.

Consent from the Ethical board committee of Kathmandu Medical College Teaching Hospital was taken as per the Helsinki Declaration act before undertaking the study. Informed consent was taken from all patients and those who allowed entering in the study were only included in the study.

Visual acuity was recorded with Snellen's chart. Anterior segment and posterior segment of the eyes were examined with Heine slit lamp. Anterior chamber of all cases and controls were assessed with slit lamp. Posterior segment of the eyes were examined with $90 \mathrm{D}$ lens to assess disc cupping and neuroretinal rim. Visual field was assessed in all cases. In controls, visual field was performed in individuals with cupping $>0.5: 1$ only or when cup disc ratio (CDR) asymmetry between two eyes was $>0.2: 1$. Automated perimetry was performed for assessing visual field. When patients were not co-operative with perimetry tests or perimetry tests revealed reliability error, then OCT (optical coherence tomography) was performed on those individuals to assess optic nerve fibres. Intraocular pressure of both cases and controls were assessed with applanation tonometry with two readings and the mean of those readings were recorded. Blood pressure was measured with a mercury sphygmomanometer two times at twominute interval after five minutes of rest in the sitting position. Auscultatory systolic and diastolic values were taken at the time of the first and fifth Korotkoff sound, respectively. The average of the two measurements was considered for the analysis.

\section{Inclusion criteria}

Cases were the people with history of hypertension and on anti-hypertensive medications recent and old, with open angle glaucoma diagnosed on the basis of IOP, disc changes and visual field defects, who were already on glaucoma treatment, who smoked and consumed alcohol in past and had quitted those substances for at least five years.
Controls were the people with history of hypertension, recently on anti-hypertensive medications, who were old and who smoked and consumed alcohol in the past and had quitted those substances for at least five years.

\section{Exclusion criteria}

Cases and controls with diabetes, myopia, migraine, hyperlipidemia, cardiovascular diseases, who were smokers and consumed alcohol, who had undergone any ocular surgeries or laser treatment and those who did not allow consent to enter in the study.

There were 40 glaucoma patients with hypertension and 100 controls with hypertension but without glaucoma included in our study. It was non-randomised sampling study with subjects of 40 years and above. The variables for this study were age, sex, systolic $\mathrm{BP}$, diastolic BP, systolic perfusion pressure, diastolic perfusion pressure, IOP and glaucoma.

Data were recorded in SPSS 17 version programme. The role of hypertension was compared with those hypertensive patients with glaucoma and hypertensive patients without glaucoma by calculating odds ratio and probability value.

\section{RESULTS}

Fifteen $(37.5 \%)$ glaucoma cases were in age group 51 60 years age group and $62.5 \%$ (25) were males. Forty six percent of control group was in $40-50$ years age group and $65 \%$ were females.

Majority 22 (55\%) of glaucoma cases had high tension, $17(42.5 \%)$ were normal tension and one $(2.5 \%)$ were ocular hypertension.

While calculating Odds ratio, age above 50 years have four times more risk to develop glaucoma than controls in our study which was statistically significant .

\begin{tabular}{|lllll|}
\hline \multicolumn{4}{|l}{$\begin{array}{l}\text { Table } \\
\text { cases and controls. }\end{array}$ Age and gender distribution of glaucoma } \\
\hline Case & $\begin{array}{c}\text { Age } \\
\text { group }\end{array}$ & Female & Male & Total \\
& & $\mathbf{n}(\%)$ & $\mathbf{n}(\%)$ & $\mathbf{n}(\%)$ \\
& $40-50$ & $1(6.7)$ & $5(20)$ & $6(15)$ \\
& $51-60$ & $8(53.3)$ & $7(28)$ & $15(37.5)$ \\
& $61-70$ & $5(33.3)$ & $9(36)$ & $14(35)$ \\
& $71-80$ & $1(6.7)$ & $4(16)$ & $5(12.5)$ \\
Total & & $15(100)$ & $25(100)$ & $40(100)$ \\
Control & $40-50$ & $33(50.8)$ & $13(37.1)$ & $46(46)$ \\
& $51-60$ & $17(26.2)$ & $7(20)$ & $24(24)$ \\
& $61-70$ & $11(16.9)$ & $9(25.7)$ & $20(20)$ \\
& $71-80$ & $4(6.2)$ & $6(17.1)$ & $10(10)$ \\
Total & & $65(100)$ & $35(100)$ & $100100)$ \\
\hline
\end{tabular}


Male genders have three times more risk for developing glaucoma than controls in this study and had strong positive association.

Low diastolic perfusion pressure was found to be significantly associated with glaucoma.

\begin{tabular}{|c|c|c|c|}
\hline Risk factors & $\begin{array}{l}\text { Odds } \\
\text { ratio }\end{array}$ & $\begin{array}{l}\text { 95\% } \\
\text { interval } \\
\text { Lower } \\
\text { limit }\end{array}$ & $\begin{array}{l}\text { Confidence } \\
\text { Upper limit }\end{array}$ \\
\hline $\begin{array}{l}\text { Age }>50 \text { yrs: }=<50 \\
\text { yrs }\end{array}$ & 4.827 & 1.862 & 12.571 \\
\hline Male:Female & 3.100 & 1.356 & 7.146 \\
\hline $\begin{array}{l}\text { Systolic blood } \\
\text { pressure > 140: } \\
<=140 \mathrm{mmHg}\end{array}$ & 1.476 & 0.627 & 3.476 \\
\hline $\begin{array}{l}\text { Diastolic blood } \\
\text { pressure }>90:<=90 \\
\mathrm{mmHg}\end{array}$ & 1.348 & 0.587 & 3.096 \\
\hline $\begin{array}{l}\text { Systolic perfusion } \\
\text { pressure } \\
<=140:>140 \mathrm{mmHg}\end{array}$ & 1.861 & 0.649 & 5.335 \\
\hline $\begin{array}{l}\text { Diastolic perfusion } \\
\text { pressure }<=60:>60 \\
\mathrm{mmHg}\end{array}$ & 3.857 & 1.362 & 11.224 \\
\hline $\begin{array}{l}\text { Intraocular pressure } \\
>21:<=21 \mathrm{mmHg}\end{array}$ & \multicolumn{3}{|c|}{$\begin{array}{l}\text { Fischer's Exact test } p \text {-value } \\
<0.001\end{array}$} \\
\hline
\end{tabular}

High systolic blood pressure and high diastolic blood pressure were weakly associated in our study. Low systolic perfusion pressure was also weakly associated with POAG.

Intraocular pressure was significantly higher $1>21$ $\mathrm{mmHg}$ ) in glaucoma patients than in controls. Fischer's Exact test was calculated for this risk factor as there were no controls with IOP $>21 \mathrm{mmHg}$.

High systolic lodds ratio: 1.59 with $95 \% \mathrm{Cl} 0.323-$ 7.848) and high diastolic blood pressure (odds ratio: 1.714 with $95 \% \mathrm{Cl} 0.348-8.44)$ was not significantly associated with IOP $>21 \mathrm{mmHg}$ and $<=21 \mathrm{mmHg}$ though there was weak positive association.

\section{DISCUSSION}

In our study, age above 50 years (odds ratio: 4.827 with $95 \% \mathrm{Cl} 1.862-12.517$ ) and males gender (odds ratio: 3.10 with $95 \% \mathrm{Cl} 1.356-7.146)$ showed significantly positive association for the development of POAG as in other reports published. ${ }^{12,13}$
Systolic and diastolic blood pressure was not significantly associated with IOP $>21 \mathrm{mmHg}$ and $<=21 \mathrm{mmHg}$ though there was weak positive association.

However, population based Beaver-Dam study showed that intraocular pressures were significantly correlated with systolic and diastolic blood pressures at both baseline and follow up. Decreased systolic or diastolic blood pressures of more than $10 \mathrm{~mm} \mathrm{Hg}$ over five years were significantly associated with decreased IOP in this study. ${ }^{1}$ In other study done in Japan revealed that age was significantly negatively correlated with IOP while higher mean blood pressure was significantly correlated with higher IOP. ${ }^{2}$

Our study result with no significant association between IOP and blood pressure could be because of our small sample size. Other reason could be because this was cross-sectional study. However there still was a risk of high systolic and high diastolic blood pressure with IOP $>21 \mathrm{mmHg}$.

No statistically significant odds ratio was found with high systolic lodds ratio: $1.47695 \% \mathrm{Cl} 0.627$ 3.476) and high diastolic blood pressure (odds ratio: $1.34895 \% \mathrm{Cl}$ 0.587-3.096) though weak positive association was observed in POAG when compared with controls. The findings were similar as observed in other population based studies. ${ }^{1,5}$ However, cross sectional Latino population based study reported that high systolic blood pressure and low diastolic blood pressure were associated with higher prevalence of POAG. ${ }^{15}$ The controversial report might be due to ethnic group variation about the role of hypertension and glaucoma which needs further study.

Low systolic perfusion pressure was weakly associated with POAG though not statistically significant in our study. Low diastolic perfusion pressure lodds ratio: 3.857 with $95 \% \mathrm{Cl} 1.362-11.224$ ) on the other hand showed significant positive risk factor for POAG which was similar to other population based studies ${ }^{1,2,5}$ Several studies both hospital and population based has revealed that lower systolic and diastolic perfusion pressure increases the occurrence of POAG including NTG, ${ }^{1,2,16}$ which was similar to our study findings.

In a similar hospital based study like ours low blood pressure was found in both progression of POAG glaucoma and normal tension glaucoma. ${ }^{16}$ The study revealed statistically significant low systolic blood pressure in glaucoma cases than in controls. The diastolic blood pressure was not statistically different in those two groups.

Though our study was not population based and it may not represent all Nepalese population or all 
population with POAG but this study does show role of blood pressure and perfusion pressure in cases with glaucoma. The statistically insignificant positive association between blood pressure, systolic perfusion pressure and glaucoma in our study might be due to small sample size.

We do recommend further population based study in Nepal to further assess the prevalence and incidence of POAG and to assess the impact of hypertension in glaucoma.

\section{CONCLUSIONS}

Age above 50 years, male gender and low diastolic perfusion pressure were strong risk factor for the development of POAG in our study. High systolic, high diastolic blood and low systolic perfusion pressure was also observed as risk factor for POAG but was statistically insignificant.

We recommend screening of every hypertensive patient for glaucoma and control of hypertension but not aggressive control leading to systemic hypotension and low perfusion pressure which was the statistically significant risk factor seen in our study for glaucomatous damage.

\section{ACKNOWLEDGEMENTS}

We acknowledge Assistant Professor Mr Umesh Aryal, Statistician and Associate Professor Sunil Kumar Joshi, Community Department from Kathmandu Medical College Teaching Hospital for their kind help in analyzing our data and giving intellectual support.

\section{REFERENCES}

1. Klein BEK, Klein R, Knudtson MD. Intraocular pressure and systemic blood Pressure: longitudinal perspective: the Beaver Dam Eye Study. Br J Ophthalmol. 2005 Mar;89(3):284-7.

2. Kawase K, Tomidokoro A, Araie M, Iwase A, Yamamoto T. Ocular and systemic factors related to intraocular pressure in Japanese adults: the Tajimi study. Br J Ophthalmol. 2008;92(9):1175-9.

3. Mcleod SD, West SK, Quigley HA. A Longitudinal study of the relationship between Intraocular and blood pressures. Invest Ophthalmol Vis Sci. 1990 Nov; 31(11):2361-6.

4. Peresalo R, Raitta C. Low blood Pressure: a risk factor for nerve fibre loss in institutionalized geriatric glaucoma patients. Acta ophthalmologica. 2009;68(S195):65-7.

5. Nicola Orzalesi, Luca Rossetti, Stefano Omboni. Vascular risk factors in glaucoma: the results of a national survey. Graefe's Arch Clin Exp Ophthalmol. 2007 Jun; 245(6):795-802.

6. Drance SM. Some factor in the Production of low tension glaucoma. Br J Ophthalmol. 1972 Mar;56(6):229-42.

7. Kaiser HJ, Flemmer J. Systemic hypotension: a risk factor for glaucomatous damage. Ophthalmologica. 1991;203(3):105-8.

8. Levene RZ. Low tension glaucoma: a critical review and new material. Surv Ophthalmol. 1980;24(6):621-64.

9. Sunde O. On the relationship between Simple glaucoma and general vascular diseases. Acta Ophthalmol. 1951;29(3):213-26.
10. Leske MC, Connell AM, Wu SY, Hyman LG, Sachachat AP. Risk factors for open angle glaucoma: the Barbados Eye Study. Arch Ophthalmol. 1995 Jul;113(7):918-24.

11. Tielsch JM, Katz J, Sommer A, Quigley HA, Javitt JC. Hypertension, perfusion pressure and primary Open-angle glaucoma: a population-based assessment. Arch Ophthalmol. 1995 Feb;113(2):216-21.

12. Wu SY, Nemesure B, Hennis A, Leske MC. Nine year change in intraocular pressure. Arch Ophthalmol. 2006 Nov;124(11):1631-6.

13. Rijal AP. Clinical analysis of Glaucoma in hospital patients. Kathmandu University Medical Journal. 2005 Jul-Sep;3(11):249-54.

14. Leske MC, Wu SY, Nemesure B, Hennis A. Incident Open-Angle Glaucoma and Blood pressure. Arch Ophthalmol. 2002 Jul;120(7):954-9.

15. Memarzadeh F, Ying-Lai M, Chung J, Azen SP, Varma R. Blood Pressure, Perfusion Pressure and Open-Angle Glaucoma: the Los Angeles Latino Eye study. Invest Ophthalmol Vis Sci. 2010 Jun;51(6):2872-7.

16. Kaiser HJ, Flammer J, Graf T, Stimfig D. Systemic blood pressure in glaucoma patients. Graefe's Arch Clin Exp Ophthalmol. 1993 Dec;231(12):677-80. 